\title{
PRÁTICAS DE EXCLUSÃO SOCIAL NO BRASIL DE JOVENS EM VULNERABILIDADE SOCIAL E DO SEGMENTO LGBTI
}

Social Exclusion Practices in Brazil of young people in social vulnerability and of the segment LGBTI

Pratiques d'exclusion sociale au Brésil des jeunes en situation de vulnérabilité sociale et du segment LGBTI

Prácticas de exclusión social en Brasil de jóvenes en vulnerabilidad social y del segmento LGBTI

\section{Mariana Rambal di ${ }^{1}$}

http://lattes.cnpq.br/3056923999278352. Mestranda do Programa de Pós-graduação em Administração pela Universidade Federal Fluminense, pós-graduada em Direitos Humanos. Graduada em Psicologia na Universidade Federal Fluminense. Interessa-se por pesquis as no campo da Saúde no trabalho, Psicologia Social e Estudos Organizacionais.

Universidade Federal Fluminense, Niterói, Rio de Janeiro, Brasil.

Marlos Coutinho Alves de Souza ${ }^{2}$ http://lattes.cnpq.br/5533201477114865.

Mestrando do Programa de Pós -graduação em Administração pela Universidade Federal Fluminense, MBA em Gestão de Negócios e Marketing, Graduado em Farmácia. Foi docente em cursos como Adminis tração, Marketing, Gestão Hospitalar e Recursos Humanos. Experiência com Marketing para a Indústria Farmacêutica. Atualmente atua como Business Controller na indústria alimentícia, Consultor e Instrutor de Educação Corporativa e Gestão de

Pes soas filiado à SBPNL. Universidade Federal Fluminense, Niterói, Rio de Janeiro, Brasil.

Suzana Canez da Cruz Lima $^{3}$ http://lattes.cnpq.br/8282852999411996. Doutora em Psicologia Social, do Trabalho e das Organizações pela Universidade de Brasília. Professora do curso de Psicologia da Universidade Federal Fluminense do Pólo Universitário de Rio das Ostras. Universidade Federal Fluminense, Rio das Ostras, Rio de Janeiro, Brasil.

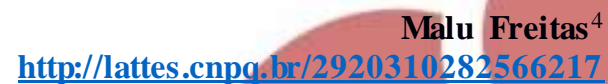

Mestranda do Programa de Pós-graduação em Administração pela Universidade Federal Fluminense. Graduada em Pedagogia na Universidade Federal do Estado do Rio de Janeiro. Interessa-se por pesquisas no campo da Saúde no trabalho e gestão escolar Universidade Federal Fluminense, Niterói, Rio de Janeiro, Brasil.

1 marianarambaldi@hotmail.com

2 m.nf@outlook.com

3 suzanacanez@gmail.com

4 maludeka@gmail.com 


\title{
Resumo
}

Neste trabalho procurou-se debater as pectos que envolvemimpasses vivenciados pelos jovens e pelo segmento LGBTI no Brasil. O objetivo é discorrer sobre práticas de exclusão de jovens em situação de vulnerabilidade e do segmento LGBTI, com base especialmente na abordagem psicossociológica. Este trabalho utilizou pesquisa bibliográfica de caráter qualitativa. Parte-se do pressuposto de que estes indivíduos sofrem inúmeras formas de exclusão situando-se no imaginário da inutilidade, os ditos “inúteis" do campo social, aqueles que vivenciam nas cenas públicas as situações mais intens as de humilhação, depreciação e de desqualificação dos seus códigos sociais e culturais. O estudo apresenta, de forma sucinta, parâmetros da trajetória destes jovens que expressam a falta de acesso principalmente à educação e ao trabalho. Quanto ao segmento LGBTI, considera-se uma população vulnerável por diferirem em termos de comportamento e orientação sexual do padrão hegemônico fixado socialmente. Neste trabalho são apresentados dados sobre atos discriminatórios oriundos do preconceito e divers as formas de violência vividas pelos LGBTI. Sugere-se a ampliação do debate em espaços sociais da luta da população LGBTI e dos jovens em situação de vulnerabilidade como forma de visibilizar o sofrimento.

Palavras-chave: Exclusão social; Jovens; LGBTI; Contemporaneidade.

\begin{abstract}
In this work we tried to discuss aspects that impasses experienced by young people and the LGBTI segment in Brazil. The objective is to discuss practices of exclusion of young people in situations of vulnerability and the LGBTI segment, based especially on the psycho-sociological approach. This work used qualitative bibliographical research. It is assumed that these individuals suffer innumerable forms of exclusion by situating themselves in the imaginary of uselessness, the so-called "useless" of the social field, those who experience in public scenes the most intense situations of humiliation, depreciation and disqualification of their social and cultural codes. The study presents, briefly, parameters of the trajectory of these young people that expresses the lack of access mainly to education to work. As for the LGBTI segment, it is considered a vulnerable population because they differ in terms of behavior and sexual orientation from the socially fixed hegemonic pattern. This paper presents data on discriminatory acts from prejudice and various forms of violence experienced by LGBTI. It is suggested to expand the debate in social spaces of the struggle of the LGBTI population and of the young people in situation of vulnerability as a way to make visible the suffering.
\end{abstract}

Key words: Social exclusion; Youth, LGBTI; Contemporaneity.

\section{Résumé}

Dans ce travail, nous avons essayé de discuter des aspects que rencontrent les jeunes et le segment LGBTI au Brésil. L'objectif est de discuter de jeunes pratiques d'exclusion en situation de vulnérabilité et segment LGBTI, sur la base notamment sur l'approche psychologique sociale. Ce travail a utilisé une recherche bibliographique qualitative. Ceci est l'hypothèse que ces personnes souffrent de nombreuses formes d'exclusion debout dans limaginaire de dévalorisation, dit «inutile » le domaine social, ceux qui vivent dans des scènes publiques les situations les plus intenses de l'humiliation, l'amortissement et la disqualification de leur codes sociaux et culturels. L'étude présente brièvement les paramètres de la trajectoire de ces jeunes qui expriment le manque d'accès principalement à l'éducation pour le travail. En ce qui concerne le segment LGBTI, il est considéré comme une population vulnérable à différer dans le comportement et l'orientation sexuelle du motif hégémonique fixe socialement. Cet article présente des données sur les actes discriminatoires résultant de préjugés et de diverses formes de violence subies par les LGBTI. Il est suggéré d'élargir le débat sur les espaces sociaux et lutte contre la population LGBTI jeunes dans des situations vulnérables comme un moyen de visualiser la souffrance.

Mots-clés: Exclusion sociale; Jeunesse; LGBTI; Contemporanéité. 


\section{Resumen}

En este trabajo se buscó debatir as pectos que involucra impas es vivenciados por los jóvenes y por el segmento LGBTI en Brasil. El objetivo es discurrir sobre prácticas de exclusión de jóvenes en situación de vulnerabilidad y del segmento LGBTI, con base especialmente en el abordaje psicosociológico. Este trabajo utilizó investigación bibliográfica de carácter cualitativo. Se parte del supuesto de que estos individuos sufren innumerables formas de exclusión situándose en el imaginario de la inutilidad, los dichos "inútiles" del campo social, aquellos que vivencian en las escenas públicas las situaciones más intensas de humillación, depreciación y de descalificación de suyos códigos sociales y culturales. El estudio presenta, de forma sucinta, parámetros de la trayectoria de estos jóvenes que expresa la falta de acceso principalmente a la educación al trabajo. En cuanto al segmento LGBTI, se considera una población vulnerable por diferir en términos de comportamiento y orientación sexual del patrón hegemónico fijado socialmente. En este trabajo se presentan datos sobre actos discriminatorios provenientes del prejuicio y diversas formas de violencia vividas por LGBTI. Se sugiere la ampliación del debate en espacios sociales de la lucha de la población LGBTI y de jóvenes en situación de vulnerabilidad como forma de visibilizar sufrimiento.

Palabras clave: Exclusión social; Jóvenes; LGBTI; Contemporaneidad.

\section{INTRODUÇÃO}

Olhando por uma faceta sombria a sociedade contemporânea tem elegido como pilares de sua ética predominante o individualismo (cada um por si), a competitividade (ver o outro como inimigo) e a velocidade. Nesta configuração se exacerba a desestabilização dos coletivos de trabalho e as formas de exclusão social. Diversos autores denunciam as repercussões deste cenário. De acordo com Lima (2011), desde a fundação do Brasil a exclusão será um dos fundamentos da sua formação social. Como assinala o autor:

Grupos humanos imensos, a grande maioria de indivíduos que integram este novo sistema social, serão incorporados na condição de excluídos. Incorporados ao trabalho e excluídos dos benefícios da vida social, por mais de três séculos, excluídos até do reconhecimento de sua condição humana (Lima, 2011, p. 09).

Dejours (2004, p. 18) afirma: "O individualismo é uma derrota e não um ideal, frente ao individualismo resta a solidão". Ele mesmo denomina as patologias mais recorrentes relacionadas à situação de trabalho como patologias da solidão, uma vez que estão intimamente ligadas à desarticulação do coletivo.

Tal lógica se sustenta pela ideologia da excelência, sistema de pensamento que produz uma visão da realidade definida especialmente pela busca de sucesso e de desempenho, pela superação de si mesmo de cunho individualista (Soboll \& Horst, 2013). Nesta bolha de realidade a vida passa a ser o trabalho, a palavra de ordem é priorizar a busca deste lugar/vencedor na corrida da competitividade mesmo que demande desligar-se da família, da alimentação e do sono. Neste ideal 
de excelência, de ser autossuficiente, a vivência que predomina é a pessoa sentir-se culpada, sempre em falta, por não ter realizado todas as metas.

A abordagem psicossociológica indica que há dois imaginários prevalentes, indissociáveis: este, o da excelência e o da inutilidade. Enquanto o imaginário da excelência enfatiza os valores de poder, carreira e qualificação social, o outro lado da moeda, é o da inutilidade que indica como centrais os valores de fracasso, de falta de inserção e desqualificação. Este é o lugar da exclusão social, onde se inserem os inúteis do campo social (Carreteiro, 2003). Assim está estabelecida uma representação dual da realidade: de um lado os sãos, resistentes, competentes; de outro lado os frágeis, inúteis. Entende-se que os rotulados como inúteis, os ditos "vulneráveis", são antes de qualquer coisa reveladores da ideologia produtivista. (Lhulier, 2015).

O presente estudo situa-se no universo deste imaginário que está enraizado na exclusão social. O objetivo é discorrer sobre as práticas de exclusão no grupo de jovens em situação de vulnerabilidade e no segmento LGBTI $^{5}$ do nosso contexto social. Esta discussão está norteada a partir de estudos relacionados sobre esta temática e a abordagem psicossociológica (Carreteiro, 2003; Gaulejac, 2006).

Sabe-se que a exclusão social abrange de forma contundente inúmeros grupos sociais tais como mulheres, os indígenas, negros dentre outros. Contudo o presente estudo elegeu como recorte para sua análise o grupo de jovens em situação de vulnerabilidade e o segmento LGBTI em função da formação acadêmica dos autores e, além disso, considerou-se que a análise de todos estes diferentes grupos sociais não seria possível dado o espaço limitado do artigo. Acredita-se que a análise da exclusão destes dois grupos se justifica dada a relevância social e científica que apresenta, uma vez que é significativo o sofrimento dos jovens em situação de vulnerabilidade e do segmento LGBTI oriundo das práticas de exclusão existentes e ainda a necessidade de estudos científicos que explorem tal realidade. Este texto não tem a pretensão de esgotar a análise sobre estas formas de exclusão, mas trazer dados importantes sobre a problemática das formas de exclusão existentes nestes dois grupos sociais específicos.

No grupo de sujeitos do imaginário da inutilidade, dos indivíduos inúteis, a experiência do sofrimento social (humilhação, vergonha e falta de reconhecimento) se faz muito presente. É nas categorias mais subalternizadas que estão as situações mais intensas de humilhação, de depreciação

5 Neste estudo, optou-se por utilizar a sigla LGBTI como forma de visibilizar a população intersexo. A sigla significa lésbicas, gays, bis sexuais, travestis, transexuais, trans gêneros e intersexos. 
e de desqualificação dos seus códigos sociais e culturais que produzem o sentimento de vergonha. De acordo com Carreteiro (2003) a hipótese que se coloca é que "este sofrimento não tem visibilidade; ele se inscreve no interior das subjetividades sem, no entanto, ser compartilhado coletivamente".

Diante desta hipótese, na concepção psicossociológica pode-se visualizar uma dinâmica recorrente. A lógica da desqualificação e depreciação se atualizam em práticas ocorridas em cenas públicas. O efeito na subjetividade de tal vivência cotidiana é de que os sujeitos se simbolizem como inadequados. Mergulhadas nesta imagem depreciativa, as pessoas tendem a não compartilhar estes sentimentos oriundos do sofrimento social. Este silenciamento ocorre tanto pela censura pessoal como também pelos dispositivos institucionais que não contribuem para esta expressão. Os espaços institucionais sejam na educação, na saúde e no trabalho, reservam para estas pessoas o lugar que as inscreve predominantemente na lógica da inutilidade e desqualificação. Daí este é o caminho que parece ser trilhado, o processo que desemboca na invisibilidade do sofrimento social.

Assim, como aponta Carreteiro (2003) "esse processo de silenciamento dos afetos, dos quais participam as instituições e os sujeitos individuais e grupais, denominamos lógica da invisibilidade" (p.60).

\section{A problemática dos jovens em situação de vulnerabilidade}

No contexto brasileiro é aceitável que indivíduos sejam apagados, seja afastando do campo visual a imagem de um sujeito, desligando a televisão, matando alguém de categoria social mais baixa ou mantendo o silêncio diante dessas violências. Como dito anteriormente, as novas formas de exclusão presentes no nosso cotidiano produzem um predomínio dos valores de fracasso, da falta de inserção e de desqualificação (Carreteiro, 2003; Mello, 1999).

Se as categorias mais subalternizadas da sociedade já sofrem com o fato de serem "indivíduos por falta", com maiores chances de experimentar o sofrimento social, fazendo parte dos seus dias situações humilhantes, que os desvalorizam, humilham e não os reconhecem (Carreteiro, 2003) pode se indagar: Como se encontram especificamente os jovens que protagonizam uma fase marcada de transformações, neste cenário que estão sendo constanteme nte colocados à prova?

A situação dos jovens num país marcado por diversidades econômicas, culturais, sociais, 
étnicas e climáticas se configura como um risco para essa população. Para os menos favorecidos, recai o ônus da desigualdade social, em um território onde poucas são as iniciativas de resgatar jovens, educá-los e torná-los cidadãos (Cairus \& Conceição, 2010).

Dados da Agência de notícia do Instituto Brasileiro de Geografia e Estatística (IBGE, 2016) apontam que a taxa de analfabetismo entre pessoas com mais de 15 anos é de 7,2\%, isso significa dizer que 11,8 milhões de brasileiros não sabem ler ou escrever. Ou seja, 11,8 milhões de brasileiros não tem acesso, em geral, nem ao conhecimento de seus direitos, simplesmente por não saberem ler. Ainda nesta pesquisa, foi constatado que $51 \%$ da população de 25 anos ou mais possuem apenas o Ensino Fundamental e apenas 15,3\% concluíram o Ensino Superior. Entre os motivos que se relacionam a esta realidade de abandono escolar está a renda per capita por família no Brasil, inferior a um salário-mínimo e, consequentemente, levando ao trabalho infantil.

A caminhada é percorrida sem redes de proteção ou apoio, suas ações desviantes desequilibram o sistema familiar e social que, muitas vezes, não lhes dá alternativa. A exclusão vai se agravando e ganhando mais perversidade, pois age no cerne individual (Cairus e Conceição, 2010; Ribeiro, 2014).

Aqueles que fazem parte do imaginário da inutilidade não tem acesso garantido aos grandes projetos institucionais. O acesso à educação, saúde e trabalho são comprometidos. As poucas inscrições oferecidas marcam os jovens de forma negativa, estabilizando lugares sociais considerados inúteis (Carreteiro, 2003).

A desigualdade é um aspecto importante destacado por Ribeiro (2014) onde no topo de uma pirâmide de distribuição de renda encontram-se indivíduos portadores de diplomas universitários, residentes de bairros de luxo que, por sua vez, seus filhos seguem esses padrões de transição para a vida adulta. A base é representada por trabalhadores manuais, com baixa renda, pouca qualificação educacional e que precisam com frequência que seus filhos, jovens e crianças, trabalhem para complementar a renda familiar e deixem de acessar o sistema educacional, ou acessem de forma limitada sem poder se dedicar de forma adequada. Esta é uma situação que contribui para que estes grupos sociais se mantenham estagnados no mesmo padrão econômico de origem.

O desrespeito aos direitos trabalhistas e submissão a trabalho escravo afeta 65 mil crianças e jovens no Brasil, que são explorados desde os tempos coloniais, quando o período de escravidão permitia o emprego de crianças para todo tipo de trabalho, esta prática, apesar de ilegal ainda é 
praticada no país (Mello, 1999). O setor informal de trabalho aceita ilegalmente jovens menores de 14 anos em algumas regiões do território nacional (Ribeiro, 2014).

As crianças e jovens que não fazem parte de um mercado e, após anos de fracasso escolar, quando não são expulsas, não contam com alternativas para ter acesso à educação formal e menos ainda a expressões culturais midiáticas banalizadas (Mello, 1999). As crianças e jovens ficam excluídas de um dos direitos básicos da cidadania que é a educação.

O sistema educacional brasileiro é baseado em um currículo unificado e igual para todas as escolas, obrigadas a lecionar um número básico de matérias e conteúdos. No entanto, a qualidade do ensino tem diferenças. Poucas escolas públicas são consideradas de boa qualidade, em contraponto, as particulares possuem práticas pedagógicas avançadas, contam com mais recursos e tecnologia por cobrarem mensalidades caras, assim sendo, a maioria dos estudantes são provenientes de famílias com status socioeconômico alto. Ao chegar na Universidade a situação se inverte: as melhores universidades são públicas e não cobram mensalidades. Para ter acesso a elas, os estudantes devem se submeter a um exame de admissão, que testa seus conhecimentos. Ora, se as melhores escolas de ensino médio são particulares e as melhores universidades são públicas, a organização do sistema educacional promove a desigualdade no acesso à formação. As políticas de bem-estar social também podem ser vistas por este ângulo. Na década de 90 o governo implantou programas para integrar jovens no mercado de trabalho, no entanto, foram considerados limitados porque atingiam poucos jovens (Ribeiro, 2014).

Diante desse cenário, os jovens menos favorecidos economicamente possuem menores chances de uma ascensão social ou econômica, mesmo que frequentem o sistema educacional durante toda sua vida e até tenham acesso à Universidade e consigam se manter, seja pública ou privada. Claramente, há diferenças de acesso e de oportunidades que perpassam e marcam suas vidas. Da mesma forma, outras políticas, conseguem atingir resultados poucos representativos no que diz respeito a inserção desses jovens no mercado formal de trabalho. Além disso, os indivíduos que pertencem a camada da sociedade que não possuem um emprego ou até profissão formal, são remetidos a um lugar de não reconhecimento.

Surge, o novo conceito de precariedade e de pobreza, o de nova pobreza, contemplando os desempregados de longa duração que são expulsos do mercado e os jovens que não conseguem acesso ao "primeiro emprego". Assim, os excluídos na terminologia dos anos 90, não são residuais nem temporários, mas contingentes populacionais que não encontram lugar no mercado e vêm 
crescendo a cada dia (Wanderley, 1997).

Desta forma, o sistema capitalista em nossa sociedade gera uma massa de marginais, excluídos das condições de educação e emprego, restando estratégias de sobrevivência como o tráfico e a assistência social. A estranheza de um não lugar, caracteriza os marginais que não têm trabalho regular e acesso a patrimônios (Cairus \& Conceição, 2010).

Para as classes dominantes é difícil reconhecer o igual nos desprovidos, que são claramente tratados como desiguais, pois não são portadores da mesma humanidade que se reconhece em si e nos iguais. Os desiguais são portadores de características desabonadoras, possuem traços de caráter indesejáveis, e imagina-se um potencial violento, pouco humano. Os jovens, por sua vez, são vítimas predestinadas, porque sobretudo estão na idade de maior inquietação e demanda por experiências novas (Mello, 1999).

A economia e a educação não são por si só responsáveis por essa crescente população dos excluídos e invisíveis na sociedade. No que diz respeito à violência urbana, a mídia é parcial e não se limita a passar informações, mais do que isso: toma partido, julga, condena, aprofunda o temor e a ignorância do público. No lugar do papel de manter os indivíduos informados, usam mensagens e códigos profundamente estereotipados. Não se veem mais pessoas, se enxergam rótulos (Mello, 1999).

A mídia é uma espécie de escola paralela nos dias atuais, as crianças e adultos absorvem muito conhecimento através do meio midiático, informações estas que se não são trabalhadas com a escola, com a educação, fazem um desfavor a formação do indivíduo e pode levar a rumos perigosos (Dorigoni \& Silva, 2007).

Há por trás desses sistemas, uma sociedade docilizada e uma mídia que legitima certas práticas e reforçam estereótipos a respeito desses indivíduos, surge a ideia do indivíduo marginal e violento, o adolescente em conflito com a lei. Jovens são marginalizados das políticas públicas que poderia ser uma oportunidade de integração (Dorigoni \& Silva, 2007).

Essa situação denuncia a inoperância dos equipamentos sociais que deveriam proteger e garantir os direitos dos jovens, independentemente da classe social a qual pertencem. Isto se reflete nas estatísticas de violência contra os jovens, recebendo destaque no cenário internacional de violação de direitos humanos, principalmente pelas taxas de mortalidade juvenil (Cairus \& Conceição, 2010).

Os jovens entre 15 e 29 anos são as principais vítimas de homicídio no Brasil, entre 2012 e 
2015 mais de 30 mil pessoas nesta faixa etária foram assassinadas por ano no país. As principais vítimas são homens jovens. Os dados pertencem ao Atlas da Violência (2016), divulgado pelo Instituto de Pesquisa Econômica e Aplicada (IPEA, 2016) e pelo Fórum Brasileiro de Segurança Pública (FBSP, 2016). Ainda de acordo com esses dados, enquanto a taxa da população de uma maneira geral é de 28,9 casos para 100 mil habitantes, entre jovens a proporção é de 60,9 casos.

Na maioria das situações, não há conhecimento da autoria dos homicídios, os inquéritos são precários, os laudos sobre a morte são inexistentes muitas vezes e as investigações envolvem a noção comum de que as vítimas são "suspeitas", desta forma, são tratadas e vistas mais como réus do que como vítimas, contribuindo para impunidade (Mello, 1999).

O documento de Análise e Pesquisa de Homicídios no Brasil, produzida pelo Ministério da Justiça e o Fórum Brasileiro de Segurança Pública (2013), responsáveis pela Gestão e Disseminação de dados na Política Nacional de Segurança Pública, produzida pelo Ministério da Justiça e o Fórum Brasileiro de Segurança Pública, reafirmam que as mortes se distribuem de forma desigual na sociedade. Apontam que os bairros com atendimento menos eficiente de serviços públicos, com infraestrutura precária, baixa taxa de emprego, serviços e lazer, são os mais afetados por homicídios. No que se refere a distribuição etária, revelam que homens jovens e negros são o grupo mais atingido por essa violência. Quando o assunto é investigação, os estudos têm apontado um fraco desempenho das polícias brasileiras no esclarecimento dos crimes de homicídios.

Quando os jovens mortos pertencem às camadas ricas, a mídia clama pela punição dos culpados. Quando o extermínio dos jovens acontece na periferia, não há nomes e pressões sobre os órgãos, há um silêncio social tácito (Mello, 1999).

Diante deste quadro exposto sobre a problemática dos jovens em situação de vulnerabilidade, são visíveis as contradições de um regime que exclui grandes massas de jovens, negando-lhes o direito à infância, à escola, ao emprego, ao salário - a investigação após sua morte. Não distante dessa realidade está o segmento dos LGBTI.

\section{A problemática do segmento LGBTI}

A sexualidade é expressa como resultante do somatório de aspectos sociais, intelectuais e emocionais exclusivos dos humanos, chegando assim, ao conceito de gênero. Gênero é entendido como uma entidade não uniforme que varia entre diferentes sociedades, manifestando-se através 
de papéis sociais, modos de ser e agir desempenhados pelas pessoas, de acordo com a sua condição, exemplificados pelas relações de poder presentes na estrutura social. A identidade de gênero, portanto, está em constante construção tanto individual como nas relações sociais (Butler, 2003; Giddens, 2012).

$\mathrm{Na}$ sociedade ocidental, o padrão de comportamento sexual é retratado pela heteronormatividade, entendida como instituições, estruturas de compreensão e orientações práticas que fazem com que a heterossexualidade pareça coerente em relação à homossexualidade. A heteronormatividade adota várias formas, por vezes contraditórias passando despercebida através do uso de linguagem básica sobre aspectos sociais e pessoais. Este padrão de comportamento é percebido por um processo de naturalização que se projeta como um objetivo ideal ou moral de orientação heterossexual. Os efeitos das narrativas construídas a partir desse padrão resultam em violências e discriminações nas trajetórias da população LGBTI (Campos e Moretti-Pires, 2016). Tal comportamento é encarado como padrão, normalidade e naturalidade das relações, indeferindo as demais identidades e comportamentos que não seja de orientação heterossexual (Campos \& Moretti-Pires, 2016; Interdonato \& Queiroz, 2017).

\section{A homofobia e o estado de violência psicológica}

A violência, enquanto um complexo processo relacionado à dinâmica social, afeta a integridade física, moral, mental ou espiritual das pessoas. É um fenômeno multicausal, na medida em que se relaciona à evolução da civilização e aos instintos de sobrevivência, bem como pode assumir um caráter eminentemente social, resultante das diferenças e desigualdades existentes entre as pessoas (Natareli et al., 2015).

A homofobia é um fenômeno plural e faz referência a um conjunto de emoções e comportamentos negativos de uma pessoa ou grupo de pessoas em relação aos homossexuais. É também um dispositivo de controle que reforça a ideia de naturalização da normalidade relacionada à orientação heterossexual. Manifesta-se nas relações sociais por meio de agressões físicas, verbais, psicológicas e sexuais, associada aos sintomas psicopatológicos e sentimentos negativos, provocando medo, incômodo, ódio, repúdio, mas também em relação ao preconceito, à discriminação e à violência contra lésbicas, gays, bissexuais, travestis, transexuais e transgêneros (Natareli et al., 2015). 
Os atos discriminatórios são oriundos do preconceito concretizado pela homofobia, que é definido como o medo ou ódio em relação a lésbicas, gays, bissexuais, travestis, transexuais, fundamentado na percepção de que alguém vivência uma orientação sexual não heterossexual (Jesus, 2012).

Pesquisas indicam que a homofobia é um dos determinantes para a saúde dos adolescentes. Um estudo realizado por Blais et al (2014), com 300 adolescentes não heterossexuais, no Canadá, que tinha como objetivo entender as mais diferentes formas de bullying homofóbico, modelando as relações entre o fenômeno e seu processo de internalização e questões de autoestima, verificou que a homofobia causa efeitos negativos sobre o bem-estar, a qualidade de vida e a saúde dos adolescentes. Com isso, evidenciou a associação entre orientação sexual, ideações e tentativas de suicídio na adolescência (Teixeira-Filho \& Rondini, 2012).

O Estatuto da Criança e do Adolescente ${ }^{6}$ (ECA) garante que crianças ou adolescentes não devem ser objeto de discriminação ou violência, dentro ou fora da família. Porém, esta situação diverge da realidade dos grupos de adolescentes brasileiros, essencialmente os homossexuais, ou comumente chamados de População LGBTI, que a esta fatia da sociedade é evidenciada a violação de direitos humanos e expostos a diversos tipos de violência (Unicef, 2011).

Segundo o Ministério da Saúde do Brasil, em 2012 foram registrados 4.851 casos de homofobia, sendo que a maioria $(61,16 \%)$ das vítimas tinha idade entre 15 e 29 anos. Esses dados evidenciam a relevância e magnitude da problemática da homofobia e, apontam, também, os adolescentes como integrantes de um grupo vulnerável. Em uma análise global, pode-se inferir que os direitos à liberdade e à segurança, parecem negados a população LGBTI, de forma geral e ao adolescente.

O estudo liderado por Natarelli et al. (2015) pressupôs que adolescentes homossexuais, configuram-se como população vulnerável, tanto pela condição adolescente, quanto pela violência e exclusão que estão expostos, por diferirem em termos de comportamento e orientação sexual do padrão hegemônico fixado social, cultural e historicamente (Natarelli et al., 2015). Além disso, o estudo objetivou conhecer os tipos de violência sofrida por adolescentes homossexuais e a repercussão das práticas homofóbicas na saúde dessa população. O trabalho foi desenvolvido por entrevistas semiestruturadas com adolescentes de 10 a 19 anos residentes no estado de São Paulo,

6 Lei n(o) 8.069, de 13 de julho de 1990. Dispõe sobre o Estatuto da Criança e do Adolescente e dá outras providências. Diário Oficial da República Federativa do Brasil. Brasília (DF), 17 de julho de 1990: Seção 1:1. 
que relataram ser vítimas de violência física, verbal, psicológica e sexual. Como principais cenários para ocorrência da homofobia os adolescentes apontaram a escola, a família, e a comunidade. As violências verbal e psicológica são mais frequentes, sendo mais constante contra os adolescentes homossexuais do sexo masculino. Nesse sentido, além da agressão física foram identificados relatos pessoais e de terceiros, a respeito de ameaças de agressão dessa natureza e tentativas de homicídio. A violência verbal foi o tipo de violência em que os adolescentes significaram como de muito sofrimento. Nesses casos, essa violência foi caracterizada pelo uso de ofensas e termos pejorativos referentes à condição sexual do adolescente, mas também do uso de palavras para oprimir e pressionar. A violência psicológica, ou simbólica, foi tratada tanto como a mais preponderante, quanto àquela que compõe o cotidiano do adolescente homossexual, que enfrenta no dia a dia, situações de preconceito, opressão, tratamento diferenciado, dentre outras formas de exclusão. A violência sexual foi destacada como um risco em potencial aos adolescentes homossexuais, principalmente aos do sexo feminino, atribuindo ainda uma prevalência maior aos casos de assédio sexual, ameaças e tentativas de abuso.

Sendo assim, o texto de Natarelli et al. (2015) vai de encontro ao trabalho proposto por Carreteiro (2003) com relação à abordagem psicossociológica. Para esta abordagem, as práticas sociais e econômicas enfatizam o lugar social, onde ocorre a exacerbação de um modelo que reforça o individualismo. Com isso, alguns indivíduos estão mais propensos à possibilidade de experimentar o sofrimento social, este que deixa marcas psíquicas com pouca ou nenhuma visibilidade social, manifestada pela vergonha, humilhação ou falta de reconhecimento.

Os adolescentes declararam nas entrevistas realizadas por Natarelli et al. (2015) a dimensão e a complexidade das situações de homofobia com as quais convivem por meio de diferentes formas de manifestação, que acarretam prejuízos à sua saúde. Isso pode ser mensurado em termos do comprometimento da saúde mental e nas dificuldades para adotar hábitos de vida saudáveis. Os entrevistados demonstram uma percepção negativa de si mesmos, que podem contribuir para que eles negligenciem práticas de autocuidado, não consigam manter hábitos saudáveis e podem até desenvolver ideação suicida.

Conforme relata Carreteiro (2003), para a psicossociologia, são os integrantes de categorias subalternizadas os sujeitos e corpos que vivenciam situações que lhes desvalorizam, humilham, fazendo-os se sentirem envergonhados, participando assim de dinâmicas sociais que causam depreciação, a falta de validação dos seus códigos sociais e culturais e a desqualificação das suas 
experiências vividas. As lógicas de invalidação e de depreciação ocorrem geralmente em cenas públicas. As pessoas sentem-se desvalorizadas e diminuídas e, raramente, compartilham tais sentimentos.

Ainda segundo Carreteiro (2003), sob a ótica da psicossociologia, o segmento LGBTI da sociedade está sob efeito das humilhações implícitas, que são sutis, deixam traços apenas na dimensão psicológica dos sujeitos, sem traços corporais. Porém, sabe-se que muitos jovens LGBTI's através de diversos mecanismos psicológicos, acabam somatizando produzindo em seus corpos os efeitos de patologias psicológicas severas que, de acordo com o estudo realizado por Natarelli et al. (2015), incorrem em prejuízos à saúde.

\section{LGBTI's em situação de rua}

Em um estudo onde desenvolve-se uma análise sobre a percepção de moradores de rua, a população LGBTI está presente em diversos casos. A discussão da construção, utilização e legitimação de discursos no espaço público e privado é central quando se trata da população de rua. Neste caso, há uma junção dos âmbitos público e privado. Assim, o cenário do morador de rua é o espaço público, todavia, este espaço é negado mais do que a qualquer outro cidadão. Dessa forma, mais do que viver nela, ele constrói novos sentidos para este cenário sobrevivendo aos desafios que a falta de previsibilidade e de constância impõe (Campos \& Moretti-Pires, 2016).

De acordo com a "Pesquisa Nacional sobre a População em Situação de Rua" (Brasil, 2008), os problemas familiares correspondem a $29,1 \%$ das razões para as idas para a rua, ficando abaixo apenas do desemprego $(29,8 \%)$ e alcoolismo/drogas (35,5\%). Entretanto, neste levantamento não foi questionado o motivo do conflito familiar e não houveram questões que abordassem as relações de gênero, orientação sexual e identidade de gênero dos participantes. A revisão feita por Campos e Moretti-Pires aponta que no cenário internacional também há pesquisas com pessoas LGBTI em situação de rua, onde tal situação está relacionada à maior propensão dos jovens LGBTI serem expulsos ou saírem de casa de forma precoce, devido ao preconceito, tendo, assim, que viver nas ruas ou em abrigos quando não possuem uma rede de apoio. Fato este indo de encontro ao estudo promovido por Natarelli et al. (2015), que aponta a violência doméstica como a causa de problemas psicológicos, onde denota que a fuga para rua é às vezes a única oportunidade que o jovem LGBTI aparenta encontrar. 
$\mathrm{Na}$ literatura internacional também são descritas peculiaridades da população LGBTI moradora de rua quando comparada com a que se identifica como heterossexual: maior frequência de violência (física e sexual) no ambiente familiar e na rua, após a saída de casa. $\mathrm{O}$ estudo de Campos e Moretti-Pires aponta ainda que a população de rua LGBTI possui maior vulnerabilidade social, maior acometimento de infecções sexualmente transmissíveis (IST), uso de drogas proibidas, prostituição e venda de drogas.

Segundo a abordagem psicossociológica, essas pessoas vivenciam, frequentemente, os discursos que operam as fobias de gênero na sociedade, logo, adentrando em instituições como escola e família. Nesse processo de silenciamento dos afetos, dos quais participam as instituições e os sujeitos individuais e grupais, denomina-se lógica da invisibilidade do sofrimento. Os indivíduos que compõem o imaginário da inutilidade não encontram uma inscrição positivada nos grandes projetos institucionais, como a educação, escola, saúde e trabalho. As inscrições oferecidas pelas instituições marcam-lhes de forma negativa, estabilizando lugares sociais considerados inúteis (Carreteiro, 2003).

Para Campos e Moretti-Pires (2016) as diferenças do tipo de violência entre gays e lésbicas são relevantes, se analisadas a partir da perspectiva de gênero. As violências, em casa e nas ruas, cometidas contra as lésbicas, vinculam-se à sua condição de gênero feminino, repercutindo em assédio e violência sexual, onde o mesmo ocorre com travestis e transexuais, haja vista seu gênero feminino. Aos gays, apresentam-se através de violência física e menosprezo por serem homossexuais. Ambos os efeitos buscam ajustar corpos e performances a partir de uma racionalidade de dominação masculina. Apesar da continuidade das violências na rua, cabe salientar que a população LGBTI, objeto deste estudo, percebem a rua enquanto um lugar melhor para seguir suas vidas que a casa dos familiares.

Embasada pela psicossociologia, os sujeitos sociais estão expostos a sentimentos forjados no confronto com injustiças, onde os integrantes de categorias subalternizadas,-_experimentam situações que lhes humilham como ser humano, onde por vezes sentem-se envergonhados e em busca de uma vida mais digna na rua, já que suas instâncias primárias de relacionamento são renegadas. 


\section{Quando a violência se torna um crime}

No mundo, 72 países, estados independentes ou regiões, criminalizam a homossexualidade. Dentre estes, oito aplicam pena de morte a homossexuais, segundo levantamento divulgado pela Associação Internacional de Lésbicas, Gays, Bissexuais, pessoas Trans e Intersexuais, ILGA. Alguns países garantem proteção a esta população, como é o caso do Brasil, porém os dados estatísticos sobre a violência contra LGBTI revelam contradições. Dados coletados pelo Grupo Gay da Bahia - GGB revelam um cenário mais assustador ainda, o de violência contra a população LGBTI que ocasionam em morte, conforme mostra a tabela 1:

Tabela 1: Assassinatos contra a população LGBTI

\begin{tabular}{c|c}
\hline Ano & Quantidade de assassinatos \\
\hline 2004 & 159 \\
2005 & 81 \\
2006 & 88 \\
2007 & 122 \\
2008 & 187 \\
2009 & 198 \\
2010 & 260 \\
2011 & 266 \\
2012 & 338 \\
2013 & 312 \\
2014 & 326 \\
2015 & 318 \\
2016 & 343 \\
2017 & 445 \\
\hline
\end{tabular}

Nota: Dados recuperados do relatório organizando anualmente pelo Grupo Gay da Bahia. Fonte: https://grupogaydabahia.com.br/assassinatos/relatorios/. Adaptado pelos autores.

O mapa elaborado pela ILGA (2017) mostra uma clara divisão do mundo nesse assunto: Américas e Europa concentram os países com mais direitos para a população LGBTI. África e Oriente médio têm os países com as penas mais duras, como prisão e execução. Há particularidades em alguns países, tanto em relação aos direitos quanto à criminalização. Já o Brasil aparece no mapa como um dos países que prevê proteção contra crimes de discriminação, permite a adoção e reconhece a união entre pessoas do mesmo sexo. No entanto, a Constituição brasileira não contém proibição explícita da discriminação baseada na orientação sexual. 
Porém, nem tudo parece piorar. Em 16 de maio de 2018 foi lançado pelo governo federal brasileiro o Pacto Nacional contra Violência LGBTfóbica, assinado entre o governo federal e pelos estados da federação. Até o acesso desta notícia, treze estados brasileiros compunham o Pacto: Acre, Alagoas, Ceará, Espírito Santo, Goiás, Mato Grosso do Sul, Pará, Pernambuco, Piauí, Rio de Janeiro, Rio Grande do Sul, Rondônia e Tocantins. A proposta do Pacto Nacional de Enfrentamento à Violência LGBTfóbica divide-se em cinco eixos de atuação: prevenção; investigação e responsabilização; reparação; promoção e participação e transparência. Para cada eixo as secretarias que aderirem ao Pacto poderão propor ações que atendam os objetivos de cada eixo proposto (Ministério dos Direitos Humanos, 2018).

O pacto prevê a criação de estrutura de gestão nas Secretarias Estaduais para promoção de políticas para Lésbicas, Gays, Bissexuais, Travestis e Transexuais; a institucionalização e o funcionamento de Comitê Gestor Estadual/Distrital; a elaboração de Plano de Ações, com cronograma de execução, apresentação de resultados finais e dados estatísticos para o enfrentamento à violência LGBTfóbica nos estados; estímulo à criação de Conselhos Estaduais de Combate à Discriminação LGBT e a inserção dessas ações no Plano Plurianual (PPA), para que seja garantido orçamento para as políticas de combate à violência. (Agência Brasil, 2018).

\section{CONSIDERAÇÕES FINAIS}

O estudo buscou dar visibilidade às diversas modalidades de exclusão instituídas de forma específica nos grupos de jovens em situação de vulnerabilidade social e no segmento LGBTI.

Estes indivíduos sofrem de inúmeras formas de exclusão e se encontram no imaginário da inutilidade, onde se inserem os ditos "inúteis" do campo social, aqueles que tem experiências na sociedade, das situações mais intensas de humilhação, de depreciação e de desqualificação dos seus códigos sociais e culturais. A história destes jovens expressa a falta de acesso à educação a ao trabalho e demonstra que as estratégias de sobrevivência que restam restringem-se, muitas vezes, aos programas da assistência social e ao tráfico de drogas.

A forma como os sistemas estão impostos na nossa sociedade ajudam a manter padrões de exclusão social definidos. O sistema educacional é bem dividido e segregador, mantendo as classes nitidamente separadas. A mídia se distancia do seu papel de transmitir informações e reforça estereótipos que marginalizam. Os jovens, que poderiam encontrar apoio através de políticas públicas não tem acesso facilitado às poucas que existem. A sociedade funciona de forma 
individual e competitiva, e esses aspectos são constantemente incentivados pela escola, pela mídia, pela familia.

Ao segmento LGBTI em especial, espera-se que a sociedade produza debates mais específico haja visto o crescimento de casos de violência contra essa população, conforme relatado. Debates como estes que devem estar cada dia mais presentes nas instâncias sociais, nos lares da população brasileira através da mídia em propagandas, televisão, rádios, telejornais, novelas, política, movimentos sociais, demonstrando que a população LGBTI sofre, e muito, com a violência doméstica, nas ruas e psicológica. Ainda enfatiza-se a questão dos assassinatos desta população, que muitas vezes são invisibilizados, mal reportados ou desconsiderados por autoridades policiais, caindo no imaginário do inútil mais uma vez.

Além disso, para a promoção desses debates abertos em família, a conscientização dos integrantes de casa e a formação de cidadãos mais conscientes em respeito às diferenças e à diversidade de pessoas em sociedade pode melhorar e diminuir os índices de êxodo de jovens de suas residências. Com isso, o entendimento e aceitação da sexualidade dos jovens pode diminuir casos de infecção por doenças sexualmente transmissíveis, mortes na rua, mortes em casa, prostituição e a diminuição dos índices de evasão escolar. Paralelamente, seria interessante o desenvolvimento de um programa educacional de enfrentamento das diferenças no ambiente escolar.

Diante da exclusão, da desigualdade, da injustiça, da violência que faz parte do nosso cotidiano, como afetar o sujeito e os coletivos? Acredita-se que a reflexão crítica e o diálogo interdisciplinar entre as abordagens pode ser um caminho, bem como espaços de discussão como este que deu origem ao presente texto.

Espera-se que os governos das esferas: federal, estaduais e municipais intensifiquem o desenvolvimento de políticas públicas para a população jovem, que atinja de fato também a população LGBTI, haja vista o crescimento de casos de intolerância por parte das famílias, espaços sociais como religiões, escolas e sociais de lazer. Tais políticas públicas devem investigar, entender e flexionar o ocorrido nos espaços sociais com vistas a reduzir os casos de moradores de rua ocasionados por expulsões de suas residências, ausência de oportunidades de adentrar ao mercado de trabalho e acesso da população travesti e transexual ao ensino igualitário. 


\section{REFERÊNCIAS}

Agência Brasil (2018). Estados e governo federal firmam pacto contra violência homofóbica. Acesso em: 23/07/2018. Disponível em: http://agenciabrasil.ebc.com.br/direitos-humanos/noticia/2018-05/estados-e-governo-federalfirmam-pacto-contra- violencia-homofobica.

Blais M, Gervais J, Hebert M. (2014). Homofobia internalizada como um mediador parcial entre bullying homofóbico e auto-estima entre os jovens das minorias sexuais em Quebec (Canadá).Ciencsaude colet. mar; 19(3): 727-735.

Borelli, S. H. S., \& Oliveira, R. de C. A. (2010). Jovens urbanos, cultura e novas práticas políticas: acontecimentos estético-culturais e produção acadêmica brasileira (1960-2000).Utopía y PraxisLatinoamericana, 15(50), 57-69.

BRASIL (2008). Pesquisa Nacional sobre a População em Situação de Rua. Brasilia: Ministério Do Desenvolvimento Social e Combate à Fome.

Cairus, R.; Conceição, M. I. G. (2010). Adolescentes na corda bamba: aspectos psicossociais na relação com a lei. Rev. psicol. polít., São Paulo, v. 10, n. 20, p. 275-292.

Carreteiro, T.C. (2003). Sofrimentos sociais em debate. Psicologia USP, 14(3), 57- 72.

Castro, L. R. de. (2008). Participação política e juventude: do mal-estar à responsabilização frente ao destino comum. Revista de Sociologia Política, 16(30), 253-268.

Costa, A. T. (2013). “A Investigação de Homicídios no Brasil”. Secretaria Nacional de Segurança Pública/Ministério da Justiça e Fórum Brasileiro de Segurança Pública.

Dejours, C. (2004). Para uma clínica da mediação entre psicanálise e política: A psicodinâmica do trabalho. In V. Lancman\& L.I. Sznelwar (Org.) Christophe Dejours: Da psicopatologia à psicodinâmica do trabalho (pp.165-194). Rio de Janeiro: Fiocruz; Brasília: Paralelo 15.

Dorigoni, G. M. L., Silva, J. C. (2007). Mídia e Educação: o uso das novas tecnologiasno espaço escolar. Disponível em: <http//www.diaadiaeducacao.pr.gov.br/portals/pde/arquivos/11702.pdf. Acesso em: 28 de maio de 2018.

Fundo das Nações Unidas para a Infância (UNICEF). (2011). O direito de ser adolescente: Oportunidade para reduzir vulnerabilidades e superar desigualdades. Brasilia: p. 182.

Gaulejac, V. (2006). As origens da vergonha. São Paulo: Via Lettera. Giddens, A. (2012). Sociologia. Porto Alegre: Penso.

Grupo Gay da Bahia. (2018). Assassinatos homossexuais (LGBTI) no Brasil. https:/grupogaydabahia.com.br/assassinatos/relatorios/. Acesso em: 23/07/2018.

IBGE. Instituto Brasileiro de Geografia e Estatística. Pesquisa Nacional por Amostra de Domicílios 
Contínua (Pnad Contínua) 2016: resultado anual - microdados da amostra. Rio de Janeiro: IBGE, 2016.

ILGA (2017). Sexual orientation laws in the world - protection. https:/ilga.org/downloads/2017/ILGA_WorldMap_ENGLISH_Protection_2017.pdf. Acesso em $23 / 07 / 2018$.

Interdonato, G. L.; Queiróz, M. C. de. (2017) Trans-Identidade: A transexualidade e o ordenamento jurídico. 1. ed. Curitiba: Appris, 2017.

IPEA; FBSP. Instituto de Pesquisa Econômica e Aplicada; Fórum Brasileiro de Segurança Pública. Brasil. Atlas da Violência. (2016). Disponível em: http://www.ipea.gov.br/atlas violencia/download/2/2017. Acesso em: 24 de maio de 2018.

Jesus, Jaqueline Gomes de. Orientações sobre identidade de gênero: conceitos e termos. (2012). p. 29. Disponível em http://www.diversidadesexual.com.br/wpcontent/uploads/2013/04/GÊNERO-CONCEITOS-E-TERMOS.pdf. Acesso em: 23/07/2018.

Lhuilier, D. (2015). A intervenção em psicossociologia do trabalho. In M, R.D. \& V., A.C. (Org.). Trabalho e emancipação: a potência da escuta clínica. Curitiba: Juruá.

Lima, Luis Gonzaga de Souza. (2011). A refundação do Brasil - rumo à sociedade biocentrada. São Carlos: Rima Editora.

Ministério da Saúde (BR). (2013). SUS vai registrar casos de agressão por homofobia [online]. Brasília: Ministério da Saúde. Disponível em: http://portal.saude.gov.br/portal/saude/area.cfm?

Ministério dos Direitos Humanos. (2018). 13 estados fazem parte do Pacto de Enfrentamento à Violência LGBTFóbica. Acesso em 23/07/2018. Disponível em http://www.mdh.gov.br/todas-as-noticias/2018/julho/13-estados-fazem-parte-do-pacto-deenfretamento-a-violencia-lgbtfobica.

Mello, Silvia. Leser de. (1999). A violência urbana e a exclusão dos jovens. In B. Sawaia (Org.), As artimanhas da exclusão: análise psicossocial e ética da desigualdade social (pp. 128-140). Petrópolis, RJ: Vozes.

Natarelli T. R. P., Braga I. F., Oliveira W. A., Silva M. A. I. (2015). O impacto da homofobia na saúde do adolescente. Escola Anna Nery 19(4).

Ribeiro, C. A. C. (2014). Desigualdades nas transições para a vida adulta no Brasil. (1996 E 2008). Sociol. Antropol., Rio de Janeiro, v. 4, n. 2, p. 433-473.

Soboll, L. A.P., Horst, A.C. (2013). Ideologia da Excelência. In F.O. Vieira, A.M. Mendes \&A.R. C.Merlo. Dicionário Crítico de Gestão e Psicodinâmica do Trabalho. Curitiba: Juruá.

Teixeira-Filho FS, Rondini C. A. (2012). Ideações e tentativas de suicídio em adolescentes com práticas sexuais hetero e homoeróticas. Saúde Soc. Jul/set;21(3):651-667. 
257

Tomizaki, K. Daniliauskas, M. (2018). A pesquisa sobre educação, juventude e política: reflexões e perspectivas. Revista Proposições, V.29, N.1 (86).

Wanderley, M. B. (1997). Refletindo sobre a noção de exclusão. Serviço Social \& Sociedade, São Paulo, Cortez, n.55, p.74-83.

Whitbeck, Les et al. (2004). "Mental disorder, subsistence strategies, and victimization among gay, lesbian, and bisexual homeless and runaway adolescents". Journal of Sex Research, Abingdon, v. 41, n. 4, p. 329-342. 